\title{
ESTUDIOS
}

\section{Actividad asociativa de los emigrantes españoles en Europa}

\author{
Por Pedro de LEZAMA*
}

Desde que la emigración existe como fenómeno social, los grupos nacionales en el extranjero han tendido a unirse y asociarse por diversos motivos. No han sido excepción los españoles.

La activioad asociativa de la antigua y tradicional emigración española en América, se ha repetido en estos úl timos años en fa actual del continente europeo. Pero los motivos que han impuisado esta actividad, se puede decir que han sido radicalmente differentes.

En América los españoles se asociaron principalmente por concordancias regionales. Nostalgias y costumbres de sus lugares de origen prevalecieron en los grupos sobre otros motivos o intereses sociales. En Europa predominan los motivos y los intereses reivindicativos de matiz social y laboral. Destacan, sobre todo, la defensa de la familia con la educación y promoción de los hijos, sin que éstos lleguen a perder su propia identidad en el ambiente ex" tranjero. Y la defensa de los demás derechos cívicos y laborales conocidos, gue hoy no son respetados por falta de una legislación adecuada sobre todo lo relacionado con la inmigración.

Así, cuando la emigración española en Europa aparecía como la gran ausente del cambio operado en su patria, cuando comienzan a recaer sobre ella los efectos negativos de la crisis económica y su sítuación laboral se agrava en las naciones que la recibieron, se multiplica rápida mente su actividad asociativa.

A pesar de las restricciones existentes en algunas nax chones, para las asociaciones de extranjeros, esta vitalik

"Del equipo coordinador de actividades (S. J.) en favor de los emigrantes en Europa. 
dad asociativa espanola no encuentra freno. Los emigran. tes se organizan, se asocian y confederan sus asociacio. nes reafirmando y defendiendo su situación con relación al pais que les acoge y también con relación a su patria. que no les debe dejar desatendidos.

En este articulo se sigue la linea más vertebral del movimiento asociativo espanol en Europa, es decir, el de las Federaciones, Gestoras y Coordinadoras de las multi. ples asociaciones locales de ambito más reducido.

Entre sus fines y objetivos se insiste, sobre todo, en la lwcha entablada para lograr resolver los problemas que plantea la educacion en el extranjero de la segunda gene. ración, los hijos de los emigrantes: aprendizaje de la lengua materna en clases complementarias, bilnguismo, inadaptacion, reirasos escolares con el consiguiente "dien" ficit cultural que resulta muy negativo a la hora de buscar un empleo profesional digno. Todo esto convierte on conflichya la situación de la juventud inmigrada, ya que muy dificilmente llega a uma integración suficiente en el pars de acogida.

Dentro del movimiento asociativo de los emigrantes, y en sus reuniones, algunas de ellas de carácter interna. cional, se senala la tendencia convergente hacia la reali. zación de un Congreso Democrákico de la Emilgración Española en Europa. Este Congreso, anunciado para los utumos meses de 1980 o para los primeros de 1981, atn no se ha realizano.

Como en esta actividad asociativa de los emigranes españoles han influido shn duta de forma diversa circuns. tancias muy distintas del comienzo, desarrollo y estado actual de la emigración en cada nacibn europera, se van dando datos, nación por nación, de estas circunstancias diferentes. Muchos de estos datos están tomados de "Car" ta de Españaxnigración”, colecciones de los años 1979 y 1980.

\section{IA STUUAGON POR PAISES}

\subsection{Sukza}

En el siglo XIX Suiza exportaba mano de obra. Unos cien mil helvéticos emigraron a América. Pero a partir de 1850, al crecer aceleradamente su industrialización, la necesidad urgente de trabajadores iba a desbordar su demografía. Ya en 1890 era un país importador de mano de obra. Al comenzar la guerra europea de 1914, el boom emigratorio hacia Suiza era espectacular. En. tonces trabajaban unos 600.000 extranjeros como obreros perma. 
nentes y unos 90,000 como temporeros. Hoy se puede decir que es el país europeo con mayor numero de inmigrantes en proporción con su población activa. Uno de cada seis habitantes es extranjero.

Los españoles, que actualmente son 116.752 , comenzaron a lle. gar en 1959 de forma espontánea. Era una emigración dispersa, sin ser canalizada por ningún organismo oficlal. En 1961 emigra. ron a Suiza 4.070 españoles, según datos del Ministerio de Trar bajo español. En 1960 lo habian hecho 7.100, según la police Fé. cérale des Etrangers, y en 1962 la misma fuente suiza daba la cifra de 21.358 llegadas de españoles. Las fuentes oficiales espaholas daban cifras bastantes más bajas. La diferencia resalta bien el carácter clandestino de la emigración española hacia Suiza en los primeros años.

La sociedad suiza, en su conjunto, aparece como una de las más hostiles al trabajador extranjero. En 1961 se creó la Unión Nacional para contrarrestar la influencia extranjera. Desde entonces el poder ejecutivo ha venido exigiendo la adopción de medidas tajantes para frenar y controlar la admisión de mano de obra extranjera. Las presiones de este partido obligaron a plantear un referengan nacional en 1970. La iniciativa formulada "contra la penetración extranjera" vue derrotada. En 1974 volvieron a insistir forzando otro we ferendum con la nueva consigna de "expulsar del país medio millón de extranjeros". Esta vez no pros-

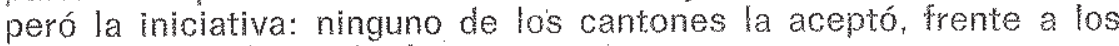
siete que aprobaron la de 1970.

Aunque no tuvieron el éxito esperado los relerendums, la situación de los trabajadores extranjeros empeoró notablemente. Disminuyó la proporción de los trabajadores contratados como permanentes y aumentó la de los trabajadores contratados como temporeros.

La categoría de trabajador temporero ocupa el escalón más bajo en el plano laboral. Llegan los temporeros a Suiza con unos contratos de una duración máxima de nueve meses. No se les permite llevar con ellos a su tamilia y se les prohibe tener hilos en Suiza. Un 34 por 100 de ellos están casados y el 90 por 100 son obreros de la construcción. El breve contrato de nueve me. ses con frecuencia no se cumple por parte de las empresas con* tratantes. Asi, desde cualquier punto de vista, ético o simple. mente humano, la situación del temporero es indigna de un país civilizado. Suiza juega con el shatus del temporero para equilibrar las necesidades coyunturales de su mercado de mano de obra. Este mismo año, el domingo 5 de abril, a iniciativa del grupo "ser solidarios", se sometió a referendum la abolición del status o categoría de trabajador temporero y la proposición de varios derechos para la población extranjera. El resultado del reterent dum fue el rechazo de la abolición por un 83 por 100 de votantes. 
No hubo mayoría positiva en ninguna región del pais. Pero la situación de los inmigrantes en Suza sigue por el camino del empeoramiento.

En este ambiente de escalada legal contra los trabajadores extranjeros, los emigantes españoles en Suza demuestran una capacidad sorprendente para organizarse, asociarse y defenderse. Cuando en los demás pafses europeos los emigrantes vivian en plena prehistoria asociativa o realizaban los primeros tanteos para unirse, surge en Suiza la ATEES-Asociación de Trabajadores Es. pañoles Emigrados en Suiza.. Es la asociación pionera en el mo. vimiento asoclativo español de los emigrantes en Europa. Sucedía esto en 1968, casi diez años antes del intenso asociacionismo de los padres de familia españoles emigrantes en otras naciones de Europa.

Tras un año de decenas de asambleas y de largos debates, la ATEES realizó su primer congreso en el mes de diciembre de 1969. Conforme a lo que dicen sus estatutos, quedó constituida como una "asociación democrática, independiente de todo poder polf́ tico, religioso y económico". Su actividad se centraría en "de. fender los derechos sociales, políticos y económicos de los trabajadores".

En el mes de febrero de 1976 se fundaba en Berna una nueva organización social de los trabajadores españoles en Suiza. Con el fin de conseguir una mayor eficacia en el enfrentamiento y resolución de los graves problemas comunes, para intercambiar experienclas y lograr una mejor formación de sus miembros (padres de familia), etc. nacía la CACEES-Confederación de Asociaciones y Consejos de Padres y Consejos Escolares Españoles en Suiza-. Se presentaba como "una de las más importantes orga. nizaciones puestas en pie por los trabajadores españoles en Furopa". Constituida entonces por 14 asociaciones de caracter local, contaba ya en 1979 con 45 asociaciones y 4.000 familias. Una de sus principales actividades está dirigida a la consideración y resolución de los problemas relativos a la sequnda generación. "Nues. tros hijos están perdiendo aceleradamente su identidad nacional, decía en una entrevista el presidente de esta Confederación, y es de la mayor urgencia que la lengua y la cultura españolas se integren en el programa oficial de las escuelas de este país."

La CACEES publica una revista de temas educativos, titulada Generación. Es la más seria y técnicamente mejor concebida de cuantas revistas españolas se editan en Sulza actualmente. Es bimensual y tiene una tirada de 3.000 ejemplares.

\subsection{Francia}

No es reciente la emigración española hacia Francia. Ya en el siglo pasado, aunque no de manera constante, se iba al país ve- 
cino en busca de trabajo. Las entradas masivas de trabajadores españoles no comienzan hasta el final de la guerra, de los años 1914 al 1918. Francia necesitaba mano de obra en 1918 y el flujo de trabajadores españoles fue considerable. Datos oficiales de. claran en el año 1918, 146.000 residentes españoles y 250.000 en 1921. Curiosamente estos primeros trabajadores españoles, en su mayoría, no se alejaron mucho de la frontera. Empleados preferentemente en faenas agrícolas, residían en las regiones del Sudoeste y del Sudeste: Rosellón, Provenza, valle del Ródano, Landas, Aquitania, etc. Hemos podido escuchar de los más ancianos, residentes en Burdeos, cómo dejaron los valles leridanos y del Pirineo aragonés, para adentrarse en grupos siguiendo el curso de la Garonne.

En 1931 la cifra de residentes españoles alcanzaba los 350.000 . $Y$ el número no había fluctuado mucho cuando llegó el final de la guerra civil española. En el año 1939 se da otra entrada masiva. Los números son impresionantes. La legación mejicana, ante el Gobierno de Vichy, cifraba un total de 528.000 españoles en agosto de 1940. Unos 5.000 murieron víctimas de la penuria y de los campos de concentración, otros 6.000 combatiendo en la guerra y 12.000 en los campos de concentración de los nazis. Calculaban que unos 50.000 tomaron el camino de América Latina, especialmente de Méjico, y unos 200.000 se arriesgaron volviendo a España.

Otra entrada masiva de españoles, la última, fue originada por el Plan de Estabilización de 1959. El Gobierno español favoreció la exportación de mano de obra y comienza un nuevo boom emigratorio. Las cifras por lo que se refiere a Francía son espectaculares: 63.000 en 1962 y 66.000 en 1966. Cuando va cediendo el número de las entradas por año, l'Office National d'Inmigration habla de 504.000 españoles residentes en Francia en el año 1971, y de 571.000 en 1972. La mayor concentración de españoles se da en la región de Paris: 144.538. En la misma capital viven 69.000. Asíllega el año 1974. Hay crisis y paro. En el mes de julio de este año Francia cierra sus fronteras a toda entrada de trabajadores extranjeros. En 1977 comienzan las medidas gubernamentales para ir devolviendo inmigrantes a sus países de origen. Se estimula oficialmente el retorno con primas, se interrumpe la expedición de cartas de trabajo para extranjeros, se suspende por tres años la reagrupación familiar, etc. Hasta se llega a crear el ambiente emocional propicio para que estas medidas sean respaldadas por la población nativa. En el año 1979, ante el proyecto de ley de Lionel Stoléru, se tranquiliza a los trabajadores españoles con una declaración oficial del mismo: "Se ha decidido no aplicar las restricciones de renovación de cartas de residencia y de trabajo a los españoles, portugueses y griegos, teniendo en cuenta su próxima entrada en el mercado común europeo." Algunos, sin embargo, por diversos motivos, retornan a España. Quedan en Francia 445.968 españoles como residentes en el año 1980. De ellos 204.000 participan activamente en el sistema productivo. De estos 204.000 
trabajan la mayor parte en la construcción y en la metalurgia. Asin mismo, 77.000 españoles, la mayoría mueres, se ocupan en trabajos domésticos.

En estos anos criticos para la omigración, el movimiento asoclativo español cobra fuerza y desarrollo en Francia. Como en Suza, hubo tambien una asociacion precursora y adelantada a rodo el movimiento. Fue la FAEFF-Federación de Asociaciones de Españoles Emigrantes en Francia-. Recibió el impulso de los centros españoles de la región de paris y aparece en el año 1968. En junto de 1969 alcanza su reconocimiento y su legalización. La FAEEF es como una primera respuesta a los problemas y necesdades de los emigrantes, a las multiples carencias que sufren en la marginación y en el olvido de la sociedad a la que sirven en el país de acogida. Después de más de diez años de existencia, la FAEEF agrupa a la mayor parte de los centros y asociaciones de emigrantes españoles en Francia. Promueve y coordina el movimiento asociativo mediante la intormación y asistencia para la constifución y puesta en marcha de nuevas asociaciones, consem jos de padres de familia, etc. Peivindica un estatuto del trabalador español equivalente al de los trabajadores de la CEE hasta la integración de España en la misma. Exige una mayor vigilancia y firmeza por parte de las autoridades españolas frente a las dis. criminaciones de las que son victimas los emigrantes. Arima como principio vital, el derecho que tienen los emigrantes a la alfabetizacion, a la formación linguistica, a la formación general y profesiond permanentes y a conservar la propia identidad cultural española. En este sentido requere la participación financiera del pais de acogida, aunque cuente con la colaboración del pais de origen. Más de 70 delegados de toda Francla participaron el dí 9 de Junio de 1979 en la Xl Asamblea General de la FAEEF, en la que se integraron 26 nuevos niembros de la Federación.

El 18 de enero de 1976 era legalizada, ante el Gobierno rrancés, una nueva asociación española, dirigida hacia la resolución de problemas sociales concretos relacionados con la familia y la educación de los hijos. Se trataba de la APFEEF-Asociación de Padres de Familia Españoles Emigrantes en Francia-. Implanada primero en Paris, pronto se extendió por toda la nación hasta constituir una Coordinadora de 61 delegaciones y asociaciones autóm nomas en distintos departamentos de Francia, con una agrupación de más de 6.300 famllias.

El problema familiar más vitas para la APFEET es el de la segunda generación: los hijos de los emigrantes que al terminar su escolarización no alcanzan, muchas veces, el nivel suficiente para ingresar en centros de formación profesional. Esto tiene luego consecuencias: no pueden obtener carta de rabajo en un empleo calificado.

La APFEEF realizó, el 9 de noviembre de 1980, su IV Asamblea 
Ceneral con la asistencla de 66 delegados de toda Francia y unas 300 personas. Los presidentes de las Federaciones de Alemenia y Holanda con el de la FAEE de Francia. insistieron en sus inter. venciones sobre la necesaria unidad del movimiento asociativo a nivel europeo. Tiene su publicación Carta be los radres con un

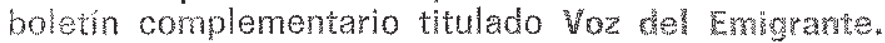

\section{$1,3$. Mmglaterra}

A hablar de la emigración española en inglaterra hay que notar ciertas características que la distinguen. Es més tardía y no tan perceptible por su número como las otras emigraciones españolas en Europa. Carte Españ la define muy bien como una vieja e Ignorada emigración". $Y$ publica una estadistica aparecida en

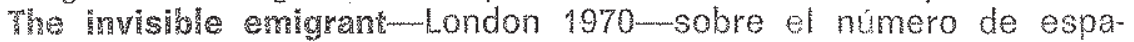
noles en Inglaterra: 1.337 en el año $1861,2.979$ en 1931 , y 2.558 en 1957. Hasta 1957 la emigración española en el Reino Unido es prácticamente inexistente. En la segunda mitad de la década de los 50, es esporádica y especialmente dirigida al trabajo domés tico. Del año 60 al 70 alcanza ya la cifra de 35.000 españoles residentes. Por cada 100 hombres hay 98 mujeres, proporción bien significativa con relación al empleo de la mayoría, porque el 90 por 100 de los trabajadores extranjeros se ocupa en la rama de la hostelería.

Hasta hace pocos años la emigración española a Inglaterra no ha sido controlada por ningún tipo de convenios. Abandonada a los abusos de las agencias de colocación, ha sido reclutada por gestiones personales de emigrantes residentes alli, que iban en. ganchando gente de sus mismos pueblos. Por eso la actividad de esas agencias se centró en determinadas regiones. Por otra parte, Inglaterra es tremendamente restrictiva en todo lo que se refiere a permitir la entrada de trabaladores extranjeros. Con la crisis económica, el Gobierno adoptó medidas más severas para restringir las entradas. Medidas que afectaron a los españoles, prácticamente indefensos, al no pertenecer España al Mercano Común. Hoy se puede decir que nuestra emigración al Peino Unido está derenida.

En esta situación de soledad, de clandestinidad, de desinfor. mación y de dispersión, tiene un gran mérito el encontrarse, el comunicarse y organizarse en centros españoles, y más aún el unirse formando asoclaciones. Por todas estas dificultades, el mo. vimiendo asociativo de los emigrantes españoles en el Reino Unido es naturalmente más tardío y reciente.

El movimiento surgió de los diversos centros españoles que deseaban establecer lazos de cooperación en todo lo relacionado con la problemática de la emigración española en el Peino Unido. Así, en un encuentro de representantes de 12 centros y asocla- 
ciones, quedó constituida FAEERU Federación de Asociaciones de Emigrantes Españoles en el Reino Unido-, en Londres, el día 14 de marzo de 1976. Las reivindicaciones planteedas por FAEERU se concretan especialmente en el terreno de la enseñanza, de la formación profesional, y sobre las limitaciones y los defectos del Convenio de Seguridad hispano-inglés que entró en vigor el 1 de abril de 1975.

El 2 de octubre de 1977 quedó constituida otra Asociación de Centros y Asociaciones de Españoles en el Reino Unido-ACADE-. Según sus estatutos, los temas más importantes que ocuparian su actividad iban a ser: la revisión del Convenio de Seguridad Social hispano-ingles, la defensa del derecho del emigrante al retomo, la exigencia de la participación democrática de los emigran tes en todas las decisiones que afecten al mundo de la emigración, etc.

Después de muchas dificultades, las Asociaciones de padres de Familia Españoles del Reino Unido lograron unirse en un em. peño común frente a los problemas de la educación de sus hijos en los centros escolares ingleses. Su misión especifica iba a ser la defensa de los intereses en la educación y de la promoción de la segunda generacion en el Reino Unido, y llevar su representa. ción y su voz a los encuentros internacionales de las Asociaciones de Padres de Familia Emigrantes Españoles. Realizaron st primera Asamblea en el mes de junio de 1979 , a la que asistieron representantes de 19 asociaciones de Padres de las 44 que habian sido convocadas. Se denominó Unión de Asociaciones de Padres de Familia-UAP-... En 1980 apareció el Boletín Informativo de la UAP, orientado especialmente a los alumnos de las escuelas españolas en Inglatera. También FAEEPU tiene su revista intormativa, que ultimamente ha intensificado su periodicidad llegando a ser mensual.

\subsection{Alemania}

La emigración española a la RFA es moderna y no tiene esa historia aventurada de las emigraciones españolas dirigidas a otros paises europeos. Porque desde que comenzó fue la más reglamentada y la que quizá ha contado con mayor número de medios comparándola con las demás. La dificultad del idioma y las mismas costumbres alemanas, inclinaron al Gobierno español hacia un sistema proteccionista. Por otra parte, los empresarios en la época del "milagro alemán "tenian necesidad de disponer con urgencia de abundante mano de obra extranjera. Esto contribuyó mucho también a la reglamentación y al orden de la emigración española a Alemania.

En 1960 se firma el primer acuerdo sobre emigración española a la RFA. Ya a partir de 1955 se había notado la llegada incon- 
trolada de españoles. Al comienzo de la década de los años 60 se produce la emigración masiva dirigida hacia Alemania. Todas las semanas salian regularmente trenes especiales llevando unos 600 emigrantes, despues de haber sido sometidos en Madrid a los exámenes médicos y a los formulismos exigidos por las autoridam des alemanas.

Millares de españoles, procedentes en su mayor parte de las regiones rurales y económicamente más deprimidas, llegaban a Ia RFA más llenos de ilusiones que de preparación para la realidad ambiental que les esperaba. El choque frontal con la barrera de un idioma difícil, la marginación del alojamiento en barracas, la inadaptación al trabajo encargado, etc., fueron causa, para algunos de ellos, de perturbaciones mentales y de pérdida de su identidad (1).

En 1966 eran ya casi 200.000 los obreros españoles que trabajaban en la RFA. Y precisamente en este mismo año se produce la primera crisis. Decenas de miles de españoles tienen que regresar al quedarse sin empleo. Pero el colapso laboral fue breve. Tras las negociaciones de 1967. Alemania abre de nuevo sus puertas y comienzan otra vez las liegadas de trabajadores españoles. La situación legal se estabiliza. Aparecen nuevas leyes de protección. Pero simultáneamente aparecen también nuevos problemas: se niega casi siempre la reagrupación familiar, empiezan a pesar las dificultades de la educación de los hijos que van creciendo en Alemania, etc. Y lo que es mucho peor, se echa encima la actual crisis económica con su consecuencia fatal: el paro cre. ciente. En 1973 se cierran las fronteras alemanas a todo obrero que no pertenezca al Mercado Común. Los españoles, que habían alcanzado la cifra de 212.000 en 1973 , tienen que ir abandonando Alemania aunque tengan contratos, papeles de residencia y trabajo en regla. Regresar es su destino ante los obstáculos de orden administrativo que no pueden superar. El resultado de estas medidas, arbitrarias en muchos casos, es el retorno precipitado dejando viviendas a medio pagar, malvendiendo enseres, truncando la instrucción escolar de sus hijos. En tres años vuelven a España más de 100.000 españoles. Alli quedan 182.000, siendo un 21 por 100 de ellos jóvenes.

$Y$ es precisamente en estos últimos años, en medio de un cambio sustancial operado en las condiciones del emigrante español en Alemania, cuando comienza un espectacular desarrollo de las Asociaciones de Padres de Familia. Sus actividades se dirigen hacia el problema más difícil y espinoso: la educación de los hijos en un país en el que la integración de la juventud extranjera es extraordinariamente conflictiva. No hay más que recordar es-

(1) Boletín Informativo del Instituto Español de Emigración. Gabinete de Estudios y Estadistica. núms. 145-146, julionagosto de 1980. "Análisis de una encuesta realizada entre trabajadores españoles inmigrados en la RFA", páginas 3 a 15 . 
tos datos: el 60 por 100 de los hijos de emigrantes no alcanza el titulo de Graduado Escotar, solo el 4 por 100 de niños extranjeros pasa a escuelas superiores en comparación del 30 por 100 de los ninos alemanes. Hay que notar que esta preocupación afecta a familas españolas que se quedan en Alemania con escasas perspectivas de retorno. Luchan para que sus hijos no pierdan la pro pia lengua, cultura e identidad, en Alemania, y tambien contra toda clase de discriminación de los hijos de los trabajadores ex tranjeros.

Considerando estos breves datos no sorprende la proliferacion de Asociaciones de Padres de Familia Españoles en la RFA durante los años 1978 y 1979. Pronto llegan a la Confederación de Asociaciones que une en un interés común a trabajadores españoles de las más diversas ideologías. Esta unión supone más de 0.000 familias sspañolas organizadas en 128 Asociaciones, con un número de ninos que sobrepasa los 16.000 . Así se ha creado 'una base de un potencial importante entre los emigrantes españoles de la RFA. EI trabajo que realzan estas asociaciones, tanto a nvel organizativo como reivindicativo, es muy notable. Los problemas que pretenden resolver siguen sin soluciones, porque esto no puede alcanzarse a nivel de base, sino politico y qubernamental. Por eso es de suma importancia que la Confareración sea reconocida como interlocutora válida en la PFA y en España. La Confederam ción tiene su organo informativo: Carta los padres. Ya venia pu. blicandose antes, pero la Confederación pidio que estuviese al servicio de las Asociaciones, en tanto que bsta no tuviese la sum ficiente independencla economica para suragar un boletin propio. La trada actual es de 6.000 ejemplares.

Otra bora fundamental de la Confederación es la formación permanente de adultos, y centro de ella la preparación de los miembros directivos de las Asociaciones.

\subsection{Bélgica}

Presentamos los rasgos más generales del desarrollo de la in." migración en Bélgica. Los extractamos de un documento estudia. do por el instutu Emula Vadervelde y publicado por Hommes es Migrations-Documents (2).

A finales de 1977 residían en Bélgica cerca de 870.000 inmi grados. $Y$ más de la cuarta parte de los residentes-240.000 de 370.000 -jamás han conocido el país cuya nacionalidad ostentan, es decir, el 27 por 100 de "los extranjeros" han nacido en Bélgica. Sus padres, que al llegar pretendian instalarse provisionalmente, se han quedado definitivamente. Ya se vislumbra la tercera genem ración de los polacos e italianos llegados a lo largo de los años

(2) Boletín Informativo del instituto Español de Emigrachón, Gabinete de Estudios y Estadística, núms. $139 \cdot 140$, pp. 4 a 36. 
1947 a 1956. Al principio Bélgica esperó brazos, vio llegar hombres, y sólo hacia los años 60 tomó repentinamente conciencia de la dimensión demogräfica de la inmigración. De hecho, en materia de inmigración. Bólgica jamás ha de ínido una politica concertada, se ha contentado con ir respondiendo a las necesidades coyur. turales de la economía. Ha ido poniendo remedio a las deficiencias estructurales de ciertos sectores industriales mediante la aportación de mano de obra extranjera y reclutándola en países cada vez más lejanos.

Bélgica ha dado muestras de la aparente "tradición acogedoraw, eliminando, de acuerdo con los tiempos, las más flagrantes discriminaciones de estatutos que separan a los inmigrados del resto de la población. No ha podido poner fin a la inseguridad constante que pesa sobre las condiciones de permanencia y de esta. blecimiento de los inmigrados. $Y$ en lo que se refiere a la reagrupación famillar de los inmigrados, jamás se ha opuesto fundamentamente a ella.

Siguiendo esta política de ir dejando a "las buenas obras" el acoger a los inmigrantes y resolver sus dificultades, Bélgica apenas se apercibió de que la población extranjera de Bruselas se triplicaba entre 1960 y 1975 , pasando de 70.000 a 212.000. Este ere el resultado de una introducción masiva de españoles, turcos, y sobre todo marroquíes, siendo la aparición de estos últimos la que puso de relieve súbitamente la necesidad de preocuparse de le aportación cultural de los inmigrantes. Y cuando Bélgica se da cuenta de esta presencia importante de comunidades extranjeras, es en los años 70 , ya en pleno umbral de la crisis.

E] paro comenzó a castigar con más fuerza a los inmigrantes porque trabajaban en los sectores laborales más vulnerables. Algunos dirigentes belgas pensaron en su repatriación, pero prevaleció la opinión de revisar la politica que habia de emplearse acerca de las condiciones de admisión al trabajo y a la residencia de los inmigrados. La presencia de comunidades importantes de extranjeros en el seno de las grandes poblaciones, reagrupadas con frecuencia en gheros por el hecho de la vivienda y manteniendo el uheto cultural" por el hecho de sus origenes, plan teaba problemas de dificultades especificas, muy especialmente en el plano de la inserción escolar y educación de sus niños. Es decir, se trata del problema capital de la integración de la juventud.

Esta integración se concibe no como un abandono de los va. lores culturales de origen, sino como una "cooperación entre la comunidad de acogida y las comunidades inmigradas de manera tal que cada una de ellas pueda, dentro de un espiritu de tolerancia y de respeto recíproco, desarrollar sus propios valores y acercarlos con vistas a objetivos comunes". Sólo en este santido y 70 en otro, se entenderá la integración de los extranjeros. 
En Bélgica, según la estadística publicada en 1980, hay 61.278 residentes españoles. La problemática que acabamos de señalar, la inserción escolar y la educación de la segunda generación, llevó a los padres de familia españoles hacia asociaciones de tipo local. Pronto se unieron. Bajo el lema "por una educación al servicio de los emigrantes", tuvo lugar en Bruselas los días 25 y 26 de noviembre de 1978, el Primer Congreso Federal de las Asociaciones de Padres de Familia Españoles en Bélgica FAPEB-. Las ponencias presentadas al Congreso dieron lugar a interesantes debates. Uno de los temas más discutidos fue el de la enseñanza complementaria española, otro el de la formación para adultos. Una vez más se puso de relieve que una de las preocupaciones del trabajador español fuera de su patria es la de la enseñanza y educación de sus hijos. Enseñanza que se debe mejorar. Se dijo en el Congreso que no resultaba alentador, por ejemplo, el hecho de que los italianos y turcos, dispongan de mejores medios pedagógicos para la educación de sus hijos en Bélgica, que los españoles.

Después de algunas reuniones preparatorias en todo el país. los dias 3 y 4 de febrero de 1979, se celebró en Bruselas la Pri. mera Asamblea del Movimiento Asociativo de los Emigrantes Españoles en Bélgica. Se aprobaron los estatutos y se eligío democráticamente la nueva Coordinadora Nacional. Se trataron temas relacionados con la enseñanza, con la mujer, con la juventud y con la problemática del retorno.

\subsection{Holanda}

Al comenzar el año 1979 había en Holanda 189.000 trabajado res inmigrantes. De ellos unos 56.000 pertenecian a naciones de la CEE y 133.431 a los demás paises. Las cifras de 45.000 turcos, 31.049 marroquies y otros norteafricanos, hacian que la proporción de inmigrantes musulmanes fuese notable.

"En 1980 las estadisticas dan la cifra de 24.800 españoles. De estos 16.320 pertenecen a la población activa y llevan más de cinco años de residencia en el 91 por 100 de los casos.

"En Holanda se sienten los efectos fuertes de la crisis. Sus 15 millones de habitantes temen al medio millón de parados que se acerca: van por los 325.000 en estos momentos, y el encontrar trabajo es muy difícil a mujeres y a jóvenes. A partir de la crisis económica, más de 10.000 españoles han regresado a su patria. Es la tercera parte de la totalidad. Los españoles que quedan apenas tienen problema de paro: alcanza sólo a un promedio de 400 personas. En lo que se refiere a la vivienda, los españoles se benefician del programa de subsidios concedidos por el Gobierno a los holandeses. El problema para la segunda generación es muy grave: los jóvenes pjerden su residencia a los dieciséis 
años si no se encuentran escolarizados. Por otra parte, no es buena la escolarización, pocos pasan a la enseñanza media y pesan sobre ellos las normales carencias de la inmigración" (3).

Es precisamente el problema de la enseñanza, el más agudo de todos los que afectan a los españoles residentes en Holanda.

"La inspección municipal de enseñanza del Ayuntamiento de Rotterdam señalaba recientemente las dificultades en que tropiezan los niños españoles en edad escolar, al tener que comu nicarse en lenguas distintas, bien se trate de la escuela o en la familia, y en este último caso, muchas veces entra en juego un tercer dialecto o idioma regional. Es decir, que los niños entran permanentemente en contacto con tres lenguas diferentes: la lengua regional, el español oficial y el holandes, lo que dificulta su escolarización... Según datos del Ministerio de Educación holandés, asciende a 4.000 el número de alumnos españoles escolarizados en la escuela holandesa, menores de quince años. En la enseñanza pre-escolar, párvulos, no se imparten clases de español, siendo esta la causa probable del bajo rendimiento en el prim mer curso de la enseñanza complementaria española. Sin embargo, el resultado de los experimentos realizados en escuelas de Rotterdam, Utrech y Beverwijk, donde se ha Impartido enseñanza bicultural a un grupo de párvulos españoles, ha sido altamente positivo en vistas a preparar al niño para el comienzo del período escolar, tanto holandés como español. Seria, pues, de desear se generalizara este tipo de preparación para los párvulos españoles. Al parecer, el Ministerio de Educación holandés, consciente de tal situación, consultará probablemente con la Confederación de Aso. ciaciones de Padres de Familia, sobre el nuevo Proyecto de Ley de Educación, antes de su presentación en el Parlamento, en el que se prevé la incorporación de la enseñanza del español como asignatura obligatoría en la escuela holandesa" (4).

Esta Confederación de Asociaciones de Padres de Familia Españoles en Holanda-CAPFEH--, a la que se alude anteriormente, celebró el domingo 23 de marzo de 1980 su tercera Asamblea General en Utrech. Asistieron 30 representantes de las Asociaciones de Padres de Familia confederadas. En esta Asamblea se trató del buen clima de relaciones con el Ministerio de Educación holandés, y del propósito que tiene de consultar a la Confederación sobre varios aspectos de la escolarización de los niños espanoles. La CAPFEH es la única organización de padres de familia extranjeros existente en Holanda.

Otro movimiento asociativo, el de Centros Españoles y Aso-

(3) Boletin Informativo del Secretariado de la Comisión Episcopal de Migraciones, núm. 188, 1981, p. 11.

(4) Boletín Informativo del Instituto Español de Emigración, Gabinete de Estudios y Estadistica, núms. 145-146, 1980, pp. 44-45. 
ciaciones de Holanda, llegó a federarse constituyendo la FECAH - Federación Española de Centros y Asociaciones de HolandaE dia 10 de febrero de 1979 tuvo lugar en los locales de la Fede. ración de Españoles de Brobante Occidental, una asamblea general de la FECAH. Asistieron representantes de 10 centros y asoclaciones. Se eligio Junta Directiva y se aprobaron los estatutos an los que se especifican los objetivos de la Federación: luchar por la resolución de la amplia problemática de la inmigración en Holanda, con una atencion preferente a la formación de la segum. da y tercera generación.

\subsection{Suecie}

El movimiento migratorio europeo en Suecia es un caso especial. La inmigración es un fenómeno muy reciente. El primer sum perávit entre inmigración y emigración se dio en 1930. Las esta disticas formales sobre el movimiento migratorio no comienzan hasta la década del 40 al 50 . Sus primeros inmigrantes fueron los finlandeses, sus vecinos del Norte, que tienen un estatuto privilegiado. Los inmigrantes de otros paises europeos fueron llegando en oleadas producidas por los cambios políticos en sus países de origen: polacos, húngaros, checoslovacos y griegos. A partir de los años 50 comenzaron a llegar trabajadores extranjeros a través de las oficinas de reclutamiento de mano de obra. En la actualidad, es más difícil entrar por el desempleo que existe.

La inmigración en Suecia ha sido un fenómeno masivo, porque de los 8.200 .000 habitantes, alrededor de 1.000 .000 son inmigrados, incluyendo en esta cifra a los que han adquirido la nacionalidad sueca, unos 300.000 , y otros 300,000 niños nacidos de padres (uno de los dos al menos) inmigrantes.

Mirándola bajo los aspectos étnico y sociológico, la inmigración ha sido también un fenómeno revolucionario. Porque Suecia era una unidad culural y lingüística cerradamente homogénea, exceptuando las dos pequeñas minorías, lapona y finlandesa, en el Norte. El país parece que no ha tomado conciencia aún de lo que esta pluralidad va a significar a la larga. Pero los sociólogos comienzan a preguntarse cómo reaccionarán los suecos y cómo los inmigrantes cuando haya crecido la segunda generación.

Los españoles son relativamente pocos: unos 4.000 según la Embajada, o 3.500 señalados en la estadística del I. E. E. Entre ellos hay familias cue emigraron por motivos económicos y pan rejas hispano-suecas como resultado de las temporadas de verano en Espana. Una estadistica oficiat que comprende desde el año 1962 al 1978 , da una cifra de 2.364 españoles nacionalizados como suecos. Más numerosos que los españoles, y quiá más necesitabos, son los latnomentcanos. Solo chilenos, habian entrado 
en Suecia 5.435 hasta fin del año 1978. Y siguen llegando. Detrás de los chilenos, en menor número, hay argentinos, bolivianos, uru guayos, etc. Como hispanoparlantes, ellos y sus hijos, comparten con los españoles los problemas y las dificultades del aprendizaje y asimilación de la lengua y cultura suecas, y de la integración social y laboral en el país.

El movimiento asociativo español a nivel federativo comenzó en el año 1978. El sábado 10 de junio tuvo lugar la Asamblea constitutiva de la Federación de Inmigrantes Españoles en Suecia, conocida por las siglas-FIEAS/SPFS-. Antes de cumplir su primer año de existencia, se celebró el 19 de mayo de mayo de 1979, en Estocolmo, la reunión anual del Consejo Federal que la rige. Asistieron 22 representantes de las asociaciones miembros y se llevó a cabo la elección de la Comisión Ejecutiva para el próximo perío. do. Uno de los objetivos, considerado como prioritario por los asistentes, fue el de tomar contacto con las asociaciones que no pertenecían a la Federación y con grupos de españoles que aún se encontraban sin organizarse en asociaciones, para ayudarles en este intento asociativo y federativo. De esta forma extendían y fortalecian la Federación.

En Suecia, como en otros países europeos de lengua especialmente difícil para los hispanoparlantes, se presenta el problema del aprendizaje necesario de la lengua materna en la etapa preescolar y el cultivo de la misma durante la adolescencia. No se le ocultó a la FIEAS/SRFS en esta reunión anual esta necesidad del cultivo de la lengua materna. Así decidió manifestarlo en alguna publicación y formuló una petición presentada a las autoridades suecas para que se editase una revista destinada a informar a los inmograntes sobre la importancia del aprendizaje y cultivo de la lengua materna, el derecho a recibir clases de su enseñanza, como aparece en la legislación sueca, las experiencias llevadas a cabo en este tipo de enseñanza, etc. Los destinatarios de esta revista serian todas las familias hispanoparlantes residentes en Suecia.

Precisamente fueron Finlancia y Suecia los países que en 1975 1976 encomendaron un estudio a especialistas en materia de enseñanza bilingüe para resolver el problema del bilingüismo de los inmigrantes y de sus hijos en edad escolar (5),

La conclusión del estudio es que el forzoso bilingüismo de los emigrantes es en realidad un "semilingüismo" por el que se les llega a considerar como handicapés socio-culturales. La segunda generación necesita, para poderse integrar, dominar perfectamente las dos lenguas. $Y$ para llegar a esto, se debe establecer lo más pronto posible la enseñanza pre-escolar únicamente en la lengua materna.

(5) L'Education des travailleurs migrants ef de leurs tamilles. El estudio fue publicado por la UNESCO, núm. 27. 


\section{EL MOVIMIENTO ASOCIATIVO DE LOS EMIGRANTES ESPAÑOLES EN LUCHA POR EL FUTURO DE SUS HIJOS}

\subsection{Defensa del tesoro patrimonial de la lengua y cultura propias}

La problemática global de la segunda generación emigrante española que crece en Europa es de tal importancia en su conjunto, que si se abandona su resolución en la etapa de la infanciaadolescencia, no tiene remedio después, y asi se condena a la juventud emigrante a constituir un nuevo subproletariado europeo. El "déficit educacional "del joven español en el extranjero pesa de una manera decisiva y se agrava en el momento de buscar un empleo. Entonces surgen los lamentos familiares por no haber atendido a los hijos en el aprendizaje metódico y gradual de los dos jdiomas: el materno y el del país de acogida. Este problema se endurece mucho más para los españoles cuando el idioma del país de acogida no es latino. Este es el caso de la RFA, Holanda, inglaterra, Suecia, etc.

A este problema va unido el de la integración. El buscar un difícil equilibrio entre el respeto a la propia personalidad, a la propia lengua y cultura, y la necesidad de adaptarse a la vida y ambiente del país de acogida. Hay que tomar conciencia de los límites que impone la sociedad en que se vive. Hace falta buscar y conservar la propia identidad personal en una sociedad que no ayuda, o ayuda muy poco a integrarse en ella. Es necesaria una lucha contra lo que en la sociedad impide la afirmación de sí mismo. Esto es difícil. Es una lucha por la participación en la sociedad conservando y haciendo respetar la propia identidad personal.

"Los migrantes llevan consigo su mentalidad, idioma, cultura, religión. Todo esto forma un patrimonio espiritual de pensamien. tos, tradiciones y culturas que va a sobrevivir fuera de la patria; por consiguiente, debe ser estimado en gran manera y en todas partes."

"Al idioma propio de los migrantes no le corresponde el último puesto en estas consideraciones, ya que, gracias a él, los migrantes expresan su mentalidad, las peculiaridades de su pensamiento y de su cultura, y las características de su vida espiritual."

"Siendo el idioma un camino y un medio que conduce al cono. cimiento de la intimidad del hombre y a la manifestación de esta intimidad... $(6)$.

Es admirable la lucha que entablan los emigrantes españoles en Europa para defender, a través de sus movimientos asociati-

(6) PABLO VI, Instrucción Pastoralis Migratorum Cura, Acta Apostólica Sedis 61 (1969), pp. $601-603$. 
vos, este tesoro patrimonial de la lengua y cultura propias en la educación de sus hijos. Ya hemos visto, al recorrer sumariamente la actividad asociativa en cada nación europea, cómo las Asociaciones de Padres de Familia Españoles ponen entre los primeros objetivos de cada asociación el promover el bilingüismo inicial - la enseñanza complementaria del español para sus hijos, que asisten a las escuelas del respectivo pais extranjero que les acoge.

Precisamente estas asociaciones han nacido y se han desarrollado con la idea de abordar y contribuir a la solución de los problemas educativos de todo género, de establecer contactos con las autoridades españolas y con las del pais de acogida, para conseguir una amplia promoción educativa y cultural de sus famillas.

\subsection{Realizaciones conseguidas en favor de la conservación y desarrollo de la lengua y cultura propias}

Los contactos de las Asociaciones de Padres de Familia con la administración española, por medio de las Agregadurías de Cultura en las embajadas, y sus peticiones al Instituto Español de Emigración, obtuvieron frutos inmediatos.

Anteriormente, y por Orden Ministerial de Educación y Ciencia de 28 de junio de 1969, se había creado un Consejo Escolar Primario para la enseñanza de los emigrantes españoles. Algo verdaderamente insuficiente y poco determinado. Posteriormente se modificó su composición y su denominación por otra Orden Ministerial de 16 de marzo de 1971. Se llamaba Consejo Escolar para la Extensión Educativa a los Emigrantes Españoles. El 23 de abril de 1973 se ampliaba su composición y se extendian aún más sus funciones, por nueva orden ministerial. Se ve que todo era escaso para la demanda creciente dentro de la materia de enseñanza y escolarización en el aprendizaje de la lengua y cultura españolas entre los emigrantes.

Por fin, el Consejo Escolar para la Extensión Educativa a los Emigrantes Españoles se restructuraba de manera definitiva por Orden Ministerial de 14 de junio de 1977 (7). Nacía así la Junta de Promoción Educativa de los Emigrantes Españoles. En la citada Orden Ministerial se ofrece una adecuada participación al profesorado y a los emigrantes españoles. Los representantes del profesorado serán elegidos por y entre los profesores que presten sus servicios dentro del país extranjero correspondiente. Los representantes de los emigrantes españoles serán elegidos por y entre los Presidentes de las Asociaciones de Padres de Familla Españoles existentes en el pais respectivo. En la misma Junta están representados tres Ministerios: Asuntos Exteriores, Edu-

(7) O. O. del Estadio, núm. 169, 16 de julio de 1977, p. 15995. 
cación y Ciencia, y Trabajo. Y para su funcionamiento depende de un órgano ejecutivo, denominado Vicesecretaría de Promoción Edu. cativa.

Ef funcionamiento de esta Junta Nacional de Promoción Educativa se puede calificar de desigual y discutido, a juzgar por lo que leemos en las publicaciones de los "Suplementos-Europa" (Cartas de Espańa-Emigración). Lo vamos a ver a continuación, al detenernos, en esta y en otras realizaciones educativas logradas según las características de la enseñanza y escolarización en algunos países.

\subsubsection{Suiza}

En Suiza ha funcionado muy bien la Junta de Promoción Educativa de los Emigrantes Españoles. La integraban representantes de la Embajada, Consulado, Agregaduría Cultural, Asociaciones de Padres de Familia y Maestros españoles. Se calculaba que los niños españoles escolarizados en Suiza, en edad escolar obligatoria, eran unos 12.000. De ellos asistían a las clases complementarias de español 7.512 , atendidos por 71 profesores nombrados por el Ministerio de Educación y 42 contratados por la Agregaduría Cultural, con horario parcial. El principal obstáculo educativo para el niño es que debe enfrentarse a una doble escolaridad, suiza y española. $Y$ el problema no se reduce únicamente al bilingüismo, sino a todo lo que se deriva de una doble cultura. Habría que conseguir la integración de las clases complementarias dentro del contexto de la escuela suiza, como se viene haciendo en Holanda. Pero en Suiza esto no es fácil, ya que cada cantón tiene su programa educativo. Todo depende del grado de sensibilización de las autoridades de cada lugar hacia los problemas de los emigrantes.

Con la convalidación de los estudios realizados en Suiza y las calificaciones de las clases complementarias, el alumno español está en posesión de un Libro Escolar exactamente igual que s: estuviera cursando sus estudios en España.

\subsubsection{Holanda}

La Confederación de Padres de Familia Españoles de Holanda -CAPFEH- presentó quejas, acerca del funcionamiento de la Junta Nacional de Promoción Educativa, al Ministro de Educación en ocasión de su visita realizada en el año 1979. Las diversas agrupaciones de emigrantes expresaron al Ministro su deseo de que se cumpliese lo prescrito en la O. M. de 14 de junio de 1977, referente a la representación de profesores y Padres de Familia, en la citada Junta. Porque no sería plenamente operativa, en opinión 
de las Asociaciones de Emigrantes, si en ella están ausentes las diversas asociaciones de Padres y de Maestros. Las Asociaciones de Padres, sobre todo, suponen una gran fuerza, estando coordinam das en todas las naciones de Europa, donde hay emigrantes españoles. Globalmente tienen incidencia en más de 250.000 escolares españoles en Alemania, Francia, Bélgíca, Holanda, Inglaterra y Suiza.

\subsubsection{Bélgica}

Por lo que se refiere a Bélgica, también encontramos eco de ciertas dificultades planteadas por el funcionamiento de la Junta Nacional de Promoción Educativa. En la Asamblea General de la Federación de Asociaciones de Padres de Familia Españoles en Bélgica-FAPEB-, celebrada a principios de 1979 en Bruselas, se trató casì exclusivamente de ciertas irregularidades observadas en la Junta de Promoción Educativa. La Asamblea resolvió emplazar a la Junta para que aceptara la participación de Padres de alumnos en su seno, y también en la ponencia encargada de elaborar su reglamento. La Junta de Promoción Educativa debía de haber completado su composición, en noviembre de 1977, con la participación de los representantes de las Asociaciones de Padres de Familia de Europa. Según las resoluciones de la Asamblea, la Junta ni ha completado de esta forma su composición, ni ha redactado su reglamento interno, contraviniendo la $\mathrm{O} . \mathrm{M}$. del 14 de junio de 1977 por la que fue creada. Conforme a las declaraciones de destacados miembros de la Confederación de Asociaciones, "la única parte de la Administración que se ha ocupado y pronunciado abiertamente en favor de nuestras exigencias ha sido, hasta ahora, el Instituto Español de Emigración".

\subsubsection{Inglaterra}

En esta nación puede decirse que las realizaciones oficiales en materia de enseñanza, organizada para los hijos de los emigrantes españoles, no comenzaron hasta el año 1974. Sin un censo de la población escolarizante, era poco menos que imposible para las autoridades hacer frente a un problema que, ya entonces, se perfilaba como uno de los más graves de la colonia española. Con la creación de la Agregaduría Cultural se comenzó a tomar conciencia de la urgente importancia que revestía la educación de los niños españoles en el Reino Unido. En colaboración con la Agregaduría Laboral se pudo elaborar un censo provisional y se llegó a la conclusión de que había unos 7.200 hijos de emigrantes españoles: De ellos eran escolarizables 5.300 .

Simultáneamente aparecian las Asociaciones de Padres de Familia, que si se federaron tardíamente por "la división de nunca acabar" que afectó a los primeros intentos, no por eso dejaron de 
ser aisladamente eficaces en conseguir realizaciones de enseñanza bilingüe para sus hijos.

Una de estas realizaciones es el Colegio Cañada Blanch de Londres, abierto hacia el año 1975 gracias a la magnificencia de un exportador de naranjas. Tras algunos años de adaptación, este Colegio inició una experiencia de educación bilingüe y bicultural sin precedentes.

Estudiado el problema del bilingüismo y consultadas las autoridades españolas y británicas correspondientes, se elaboró una alternativa educativa respaldada por la mayoría de los Padres de Familia Españoles. Se pensó que esta alternativa, a pesar de sus deficiencias, resultaría la más seria y válida de las emprendidas hasta entonces en materia de educación de hijos de emigrantes.

Esta alternativa del Cañada Blanch exige un profesorado compuesto, al cincuenta por ciento, por profesores británicos y españoles, que imparten el Bachillerato Internacional a niños comprendidos entre tos catorce y dieciséis años. Este bachillerato, que está reconocido por gran número de universidades de todo el mundo, entre ellas todas las británicas y españolas, permite al alumno acceder directamente a centros de enseñanza superior. Las autoridades españolas han respaldado esta experiencia, orientando totalmente la enseñanza del centro hacia el bilingüismo. De este modo, los alumnos pueden elegir a los dieciséis años entre el BUP español y los o'Levels británicos. Posteriormente se inauguró otro centro de caracteristicas similares: el colegio de Portobello.

Pero no todos, ni muchísimo menos, pueden seguir el bachillerato. Son solamente unos 205 los que lo estudian en esos colegios. La mitad de los españoles viven en el área del Gran Londres, en aglomeraciones de inmigrantes, y sus hijos asisten a escuelas en las que, muy a menudo, estudian niños de diez y más nacionalidades distintas. Todos desplazados de su lengua y cultura maternas, todos mezclados, y con un profesorado poco cualificado para el trabajo que realiza. Esta es la causa fundamental del bajo rendimiento escolar de los niños inmigrantes. Por eso se insiste en crear colegios españoles bilingües para abordar desde el principi este problema básico en la enseñanza de la segunda generación.

\subsubsection{Francia}

Las dos grandes asociaciones españolas de este país, la FAEEF y la APFEEF, se movieron eficazmente desde un principio para lograr realizaciones en el campo de la educación y formación de la segunda generación. Primero para llegar a la escolarización completa de niños y jóvenes españoles, y luego para mantener la en 
señanza de la lengua y cultura patrias dentro de la escolarización francesa.

Para ello han reclamado, siempre con insistencia, ante la Administración española, la presencia de monitores, educadores y profesores españoles especialmente preparados.

Una delegación de la APFEEF visitaba, en el mes de julio de 1978, el Ministerio de Educación y el Instituto Español de Emigración para exponerles un extenso programa reivindicativo: escasa escolarización, unos 15,000 niños españoles escolarizados en el sistema español, frente a 135.000 niños españoles escolarizados en el sistema francés. Esto demostraba el gran déficit de maestros españoles y de unidades escolares. Entre otras quejas, presentaron la de los libros de texto, a los que juzgaban como no adaptados a la específica realidad del emigrante y muy insuficientes. En fin, la APFEEF planteó el asunto de la necesaria convalida. ción de los estudios profesionales y todo lo concerniente a la formación total de la juventud española en Francia. De no ser bien resuelto este problema, se contribuirá a su marginación en un peonaje permanente.

La UNESCO, en el mismo año 1978, se dirigió a la FAEEF para llevar a cabo una encuesta sobre "Las expectativas y las aspiraciones de los emigrantes y de sus familias en materia de educación y de formación". El informe presentado por la FAEEF fue muy completo, sobre todo en lo referente al derecho de conservar la lengua y cultura de origen. Entre otros argumentos invocaba el del derecho que tiene el emigrante a escoger entre la permanencia e inserción en el país de acogida, y el retorno voluntario al país de origen con la plena reinserción familiar en el ambiente patrio. Por eso la segunda generación ha de ser educada también en la lengua y cultura patrias.

En 1979 calculaba el Agregado Cultural de la Embaiada que habría 70.000 niños en edad escolar y unos 30.000 escolarizados (en la región de París unos 10.000). Se daban clases complementarias de español hasta nivel de EGB, y además esperaban llegar a asistir pedagógicamente de esta forma a unos 30.000 alumnos, al terminar de montar todos los cursos. Unos 2,000 alumnos de Bachillerato francés recibían también clases complementarias de Lengua y Literatura españolas. Estas clases complementarias se imparten en las propias escuelas francesas, no sin alguna dificultad. Y las dificultades son mayores cuando se imparten en los Líceos a los alumnos de Bachillerato. El medio rural es el más desatendido. Quedan bastantes niños españoles sin escolarizar porque los problemas de concentración escolar son difíciles de resolver en el campo. En los medios urbanos hay colegios nacionales españoles en los que se imparten clases de EGB, y además las complementarias para los alumnos que proceden de las escue. 
las Francesas. Existe en Francia un Instituto Nacional dependiente del Ministerio de Educación y el Liceo de Neuilly en los que se cursa el Bachillerato español completo. Hoy, por la extensión que tiene la acción del INBAD-instituto Nacional de Bachillerato a Distancia-, se han multipicicado los centros de esta clase de enseñanza y se ha facilitado el acceso a ella en casi todas las regio. nes de Francia.

\subsubsection{Alemania}

El problema de la segunda generación en Alemania, tanto en lo que se refiere a su educación en la infancia, como a su posterior integración en la juventud, es el más agudo sin duda, de todos los de los países europeos en los que hay familias inmigrantes. Crece la dificultad con la existencia de diferentes gobiernos regionales de estructuras especifficamente diferenciadas, y los españoles carecen allí de un sistema educativo propio. Esto hace que las clases complementarias se impartan en los colegios alemanes, condicionados totalmente a las diversas estructuras educativas de las regiones alemanas.

Para cualquier realización, en favor de la conservación y des. arrollo de la lengua y cultura españolas, la Confederación de Asociaciones de Padres de Familla se enfrenta con grandes obstáculos. El primero es la deficiente escolarización de los niños y jóvenes españoles:

"Entre los tres y seis años, no más del 45 por 100 de niños es" pañoles asisten al Kindergarten. Sólo el 34 por 100 de los Jóvenes españoles residentes en la RFA tienen el certificado de estudios primarios. Un 10 por 100 de niños no asistieron ni siquiera a la escuela primaria. Entre los jóvenes españoles, poseen título de formación profesional; el 28 por 100 de los hombres y el 12 por 100 de las mujeres. Al bachillerato elemental acceden el 6 por 100 de los niños españoles, y a las escuelas de minusválidos el 5 por 100. El 80 por 100 de niños españoles están en las escuelas primarias, el número de los niños alemanes en estas escuelas sólo es el 59 por 100 (porque asisten a las de bachillerato)" (8).

¿Qué posibillidades de promoción tiene la juventud española en Ia RFA ante este panorama escolar? Porque la Confederación de Padres de Familia Españoles persigue como primer objetivo la integración del niño español en el sistema educativo alemán, prem tendiendo al mismo tiempo que no pierda la identidad española con el cultivo y desarrollo de la lengua y cultura castellanas. Esto quieren lograrlo desde el periodo pre-escolar.

(8) Boletin Informativo, Secretariado de la Comisión Episcopal de Migraciones, núm. 187,1980, p. 5. 
La Administración española proporciona clases complementarias dentro de las escuelas alemanas. A los españoles se les dan lecciones de lengua y cultura españolas. Esto es más difícil de lo que parece a simple vista. Muchos de los niños españoles han nacido en la RFA y se puede decir que su lengua vernácula es el alemán. Porque el contacto con sus padres es mínimo. Amigos, distracciones como la TV y el cine, etc., no es para ellos "ambiente español». La lengua de sus padres la aprenden en clase como si se tratara de un "idioma extranjero*. La Confederación de Padres de Familia ve una posibilidad ideal: un Kindergarten alemán para los niños españoles en el que se les enseñe la lengua materna española. La situación actual es que se encuentran miles de niños españoles sin hablar bien el alemán y $\sin$ conocer la cultura alemana; tampoco dominan la lengua materna y desconocen la cultura española. Son niños extranjeros en Alemania y extraños en su propio país. El problema se agrava por falta de una resolución conjunta de las diversas nacionalidades, porque lo que sucede es algo generalizado entre la juventud extranjera, hijos de inmigrantes. Cada nacionalidad requiere un modelo distinto para sus jóvenes, sean turcos, griegos, yugoslavos, italianos, portugueses o españoles.

En cuanto a la integración juvenil en el ambiente social de la RFA, la Confederación de Asociaciones de Padres de Familia se encuentra ahora ante una prometedora esperanza en este oscuro horizonte de la preparación de sus hijos para una adaptación social y laboral en su juventud.

En septiembre de 1979, el Delegado del Gobierno Federal para la integración de los extranjeros, Heinz Kühn, presentó a la política y a la opinión pública, un Memorandum muy considerado sobre la situación y evolución de la integración de los trabajadores extranjeros y sus familias en la RFA. Lo que en un principio parecía ir dirigido, más que a una integración, hacia una "germanización". con pérdida de la propia cultura e identidad, se suavizó con la intervención del círculo de coordinación de "Trabajadores Extranjeros" del Ministerio de Trabajo y Ordenación Social, las Iglesias, las Asociaciones de beneficencia y asistencia juvenil, el Instituto Federal de Trabajo, etc. Así, en noviembre de 1979, se aprobaron unas propuestas para la integración de la segunda generación de extranjeros en los sistemas educativos y de formación profesional alemanes. De estos amplios principios de política integratoria, se dedujeron unas líneas de orientación de las que citamos las si* guientes:

"La futura tarea esencial de la política de extranjeros debe ser la integración social de la segunda generación de extranjeros. Las especiales deficiencias de integración de niños y jóvenes, el cre. cimiento entre dos culturas, pero también la posibilidad ofrecida a éstos de organizar su capacidad de acción tanto individual como social, exigen esta orientación.” 
"La politica de integración, cuya puesta en práctica depende también de la cooperación de los padres extranjeros, es para los extranjeros y sus paises de procedencia solamente aceptable, si no tienen como objetivo el distanciamiento de los niños y jóvenes de la cultura patria. Por ello, especialmente en el marco de la política educativa, hay que procurar que se garantice la relación de los niños y jóvenes extranjeros con el círculo cultural de sus familias. Esto requiere especialmente que se imparta una enseñanza adecuada en el idioma materno bajo inspección alemana y el reconocimiento de la lengua materna como idioma obligatorio extranjero..."

"La integración presupone para la población alemana que esté dispuesta a reconocer plenamente la independencia cultural de los extranjeros y al mismo tiempo colaborar para su integración en nuestra sociedad" (9).

\section{3. $\angle A$ CONFEDERACION EUROPEA DE PADPES DE FAMILIA ESPAÑOLES}

El movimiento asociativo español de los Padres de Familia, que tan eficazmente lucha en cada nación por la promoción educativa de sus hijos, ha llegado a su madurez y ha potenciado su influencia al confederarse a nivel europeo y disponer de un orga. nismo coordinador con presencia internacional.

Los días 23 y 24 de febrero de 1980 , se reunieron en Colonia representantes de las Federaciones de Alemania, Bélgica, Francia, Holanda y Suiza. Una vez discutida y aprobada la necesidad de una coordinación entre todas las Federaciones, llegaron a este acuerdo y determinaron crear un Secretariado Técnico como órgano permanente de la Confederación, estableciéndolo en París.

"Parece que ante la falta de claridad en la Constitución, en Ma" drid, de una Coordinadora Europea de Asociaciones de Emigrantes, las Organizaciones de Padres han tenido que tomar esta pos. tura, ante el riesgo de ver limitada o usurpada su representativi. dad por no tener 'oficialmente' la estructura adecuada a nivel europeo."

"Buscan, de esta manera, la continuidad, la representatividad y los medios que le son necesarios para su mantenimiento y desarrollo" (10).

Los días 23 a 25 de mayo de 1980 tuvo lugar en Madrid la Asam-

(9) Boletín Informativo del I. E. E., núms. 143-144, mayo-junío de 1980, páhnas 16-42, "Evolución de la politica de extranjeros en la RFA. (Se analiza en profundidad el tema de la $2{ }^{*}$ y $3 .^{*}$ generación.)

(10) Boletín Informativo, Secretariado de la C. E. de Migraciones, número 183,1980, p. 17. 
blea Constitutiva de esta Confederación Europea-CEAPFE-. Fue la ratificación de la decisión tomada en Colonia en el mes de febrero. Asistieron 36 representantes de las Federaciones de $\mathrm{Pa}$ dres de Familia en Alemania, Bélgica, Francia, Holanda, Reino Uni. do y Suiza. Asistieron también representantes de la Administración española, y en el acto de clausura participaron el Ministro de Trabajo y el Director del Instituto Español de Emigración.

"Además de los Estatutos de la Confederación, también fueron aprobadas todas las lineas generales en materia educativa a presentar como propuestas para su integración en la futura Ley de Emigración."

"Los representantes de las Asociaciones de Padres de Familia manifestaron su deseo de colaborar en las Comisiones de Emigración del Congreso de Diputados y del Senado para que sean recogidas en el Proyecto de Ley de Emigración sus aspiraciones fundamentales."

"Se dio particular importancia, a la participación a todos los niveles, en los organismos que la Administración española ha creado o puede crear en el futuro, para la elaboración y aplicación de la política de emigración del Estado Español.»

"Otro de los aspectos fundamentales fue el reconocimiento Jurídico, no solamente de las Federaciones Nacionales y de la Confederación Europea, sino de todas las Asociaciones de Padres de Familia a nivel local, en cada ciudad de Europa, donde existen escuelas complementarias de lengua y cultura españolas, para que puedan participar en la gestión y control de estos centros educativos, que funcionan mediante la subvención de fondos pú. blicos españoles" (11).

\section{CONVERGENCIA DEL MOVIMIENTO ASOCIATIVO HACIA EL CONGRESO DEMOCRATICO DE LA EMIGRACION ESPAÑOLA EN EUROPA}

Fue la FAEEF-Federación de Asociaciones de Emigrantes Españoles en Francia-la que inspiró la iniciativa de realizar este Congreso.

En enero de 1976 se celebraba el llamado "Encuentro de Luxem" burgon, primera reunión internacional de las principales organiza. ciones asociativas de emigrantes españoles en Europa. En aquella ocasión la propuesta de la FAEEF se aprobó por unanimidad. Estimaron los reunidos en Luxemburgo que, a los problemas originales y endémicos de la emigración, se sumaban otros de orden

11) Boletin Informativo del 1. E. E., núms. 143-144, mayo-junio de 1980 , päginas 58-59. 
coyuntural agravados por la crisis económica, comunes a todos los países europeos, que estaban exigiendo soluciones urgentes. Por todo esto juzgaron conveniente el preparar y celebrar el Primer Congreso Democrático de la Emigración Española en Europa.

Pronto cobró fuerza esta idea del Congreso Democrático. Aquí y allá, en las Asociaciones locales y a nivel de las Federaciones nacionales, se pensaba y se hablaba de él como de un proyecto realizable. En casi todas las reuniones de las Asociaciones y en las de las Federaciones, se expresaba el voto favorable para llevar a cabo este acontecimiento esperanzador dentro de la situación cada vez más angustiosa de la emigración en Europa.

En el mismo mes en el que surgló la idea del Congreso, enero de 1976, se constituia provisionalmente, en la RFA, la Coordina. dora Federal Pro-Congreso Democrático, y el 6 de noviembre de 1977 quedaba definitivamente constituida y estructurada. Su objetivo era la preparación y celebración del Congreso Democrático. En él, los emigrantes españoles, de una forma concreta y organizada, podrían presentar a estudio y resolución los mútiples problemas de la emigración española en Europa.

Llega el año 1979 y todo lo proyectado sobre el Congreso De. mocrático va a tomar otro rumbo. En el mes de abril hubo un "Encuentro en Madrid" entre el Instituto Español de Emigración y algunos representantes del Movimiento Asociativo de la Emigración Española en Europa. Desde esta fecha el camino hacia el Congreso aparece, en opinión de muchos, como monopolizado por la Administración española. Ya el Congreso se denominará de otra forma. No se dirá, en lo sucesivo, Congreso Democrático de la Emigración Española en Europa, sino Congreso Democrático de las Asociaciones de Trabajadores Españoles Emigrantes en Europa.

En los días 26 y 27 de mayo tuvo lugar en París la constitución y primera reunión de la Comisión Gestora Europea del Primer Congreso Democrático de las Asociaciones de Trabajadores Españoles Emigrantes en Europa. Dicha Comisión quedó formada por representantes de 18 Federaciones y Coordinadoras de carácter nacional y por miembros de la Administración española. El objetivo que esta Comisión se propone es muy determinado: trabajar por un Congreso de Asociaciones especifficas de Emigrantes Españoles. Por tanto, el Congreso de Asociaciones no pretende representar al conjunto de la emigración. Representará a los miembros de las Asociaciones participantes y solamente a ellos, así como a sus aspiraciones especificas. No se adhirieron algunos representantes de Asociaciones y otros se abstuvieron en espera de posteriores clarificaciones. Con esto comenzó la división.

Esta Gestora Europea mostró gran actividad. Los días 30 de 
junio y 1 de julio se reunia por segunda vez en Bruselas. Allí continuó abordando el tema de su propia constitución y el del nuevo giro dado al Congreso: "Un Congreso-se decia en un comunicado-que no pretende representar al conjunto de la emigración, sino a las Asociaciones participantes solamente."

La tercera reunión de esta Comisión Gestora Europea se tuvo en Ginebra los días 25 y 26 de agosto del mismo año 1979. El primer punto de acción fue el considerar como tarea fundamental de las Asociaciones de cada país, el preparar el Congreso por medio de las Gestoras Nacionales que debían constituirse de forma inmediata.

Durante los dias 6 y 7 de octubre de 1979 la Gestora Europea realizó en Londres su cuarta reunión. Entre otros temas, se planteó alli el de las "acusaciones y ataques" de los que viene siendo objeto la Gestora Europea por parte del PSOE, que muestra su desacuerdo por la forma de preparar el Congreso y de participar en él. El PSOE no se opone al Congreso Democrático en sí, sino al que se convoca solamente dentro del marco específico de las Asociaciones.

En el año 1980 la Gestora Europea se reunió en Madrid los días 19 y 20 de enero, y durante el mismo año se fueron constituyendo las Gestoras Nacionales en los diversos países europeos, según lo acordado en la tercera reunión de la Gestora Europea en Ginebra.

Por fin, el 7 y 8 de junio de 1980 en Zurich, con asistencia del Subdirector General de Participación y Acción Cultural del Instituto Español de Emigración, la Gestora Europea trató sobre los temas que serán objeto de estudio y discusión en el Congreso Democrático de Asociaciones. En esta reunión se presentó el temario del Congreso, demasiado extenso para que to expongamos aquí (12).

Aparecido el temario del Congreso, determinadas las normas de participación de un delegado por Asociación con un voto proporcional al número de asociados, solicitado un crédito para financiar el Congreso..., éste no se ha realizado aún. $Y$ ya no se habla de él.

En cambio, una organización de carácter paralelo a la Gestora Europea, la Coordinadora Europea de Asociaciones de Españoles Emigrantes en Europa, realizaba su segunda Asamblea anual en Madrid los días 13 y 14 de diciembre de 1980. Esta Coordinadora fue creada en Bruselas en el mes de diciembre de 1978 y celebró

(12) Boletín Inforfativo del I. E. E., núms. 143-144, mayo-junio de 1980, páginas 57.58 . 
su primera Asamblea en Madrid. Ahora, después de dos años, celebra su segunda Asamblea también en Madrid. Es notable el silencio que guarda sobre todo lo relacionado con el Congreso De. mocrático de Asociaciones. "Urge una Ley de Emigración", es el tíitulo que leímos en la prensa de aquellos días como resumen de lo tratado en la cituada reunión de la Coordinadora (13).

"Dicha Ley deberia incluir el reconocimiento expreso de las Asociaciones de Emigrantes y la labor que vienen realizandon, leemos en otra información sobre la misma reunión.

Como siempre, salieron los temas palpitantes y los problemas que afectan profundamente a la familia emigrante: "Habiendo pre" sentado un estudio pormenorizado de la situación cultural en la emigración, se advirtió el serio peligro que se cierne sobre la segunda generación en Europa. Para enfrentarse a este problema, se propuso la celebración de unas jornadas de estudio sobre enseñanza, en las que participen asociaciones de padres, coordinadoras de profesores, técnicos de la Administración y la propia Coordinadora. En este sentido se abogó por la integración negociada de la lengua española en la enseñanza de cada país receptor el incremento de los presupuestos dedicados a este capítulo y la mejora de todas las publicaciones de la emigración" (14).

En el transcurso de una rueda de prensa realizada con motivo de esta segunda Asamblea, algunos miembros de la Coordinadora manifestaron: "Es necesario que la sociedad española se conciencle plenamente de que los problemas de la emigración son también sus problemas, y que las soluciones que en este sentido se apuntan han de repercutir, en definitiva, en todos los españoles, fundamentalmente en su vertiente económica, pues la cifra de aproximadamente 900 millones de dólares que anualmente entran en España procedentes de nuestros emigrantes no es algo que pueda ignorarse fácilmente" (15).

Hemos intentado exponer algo de la riqueza asociativa que han alcanzado y poseen los emigrantes españoles en Europa. Sería una lástima que por falta de la indispensable unidad de acción y por los exclusivismos, este potente movimiento asociativo de los trabajadores españoles malograse sus esfuerzos. Son muchos los problemas que les agobian. Oue no les venga encima el de la desunión y división.

(13) Diario Ya, 18 de diciembre de 1980 , p. 26.

14) "Carta de España-Emigración «, Suplemento Europa, núm. 254, rebre. ro de 1981.

115) Diario Ya, 18 de dicienbre de $7980, p, 26$. 